\author{
Learning About Article Of \\ Algoritma dan struktur data \\ Nama : Zahrullah \\ Npm : 195120017 \\ Semester : Genap (II) \\ Dosen : Arie Setya Putra.S.Kom.M.T.I \\ UNIVERSITAS MITRA INDONESIA \\ Zahrullah.student@umitra.ac.id
}

\begin{abstract}
Abstack
Didalam ilmu komputer, pemahaman tentang struktur data yang berkembang selama ini yaitu cara menyimpan, mengatur, dan mengelola data dalam media penyimpanan komputer sehingga data dapat digunakan secara efisien.

Algoritma adalah urutan langkah berhingga untuk memecahkan masalah logika atau matematika. Dalam kehidupan sehari-hari sebenarnya kita juga menggunakan algoritma untuk melakukan sesuatu. Sebagai contoh untuk menulis surat diperlukan langkah-langkah sebagai berikut :

1. Mempersiapkan kertas dan amplop

2. Mempersiapkan alat tulis

3. Mulai menulis.

4. Memasukkan kertas ke dalam amplop.

5. Pergi ke kantor pos untuk mengeposkan surat ters
\end{abstract}

Kata Kunci : algoritma langkah memecahkan logika matematika. 


\section{B. PENDAhUluan}

Instruksi harus diberikan kepada komputer agar dapat memecahkan suatu masalah. Langkah-langkah yang dilakukan untuk memberikan instruksi kepada komputer untuk memecahkan masalah inilah yang dinamakan pemrograman komputer. Pemrograman komputer bukanlah hal yang sederhana. Kegiatan ini memerlukan ketelitian dan kemauan untuk bekerja dalam jangka waktu yang lama.

Dalam komunikasi sehari-hari seorang harus berbicara dalam bahasa yang sama dengan orang tersebut. Hal ini berlaku juga untuk berkomunikasi dengan komputer. Kita harus menggunakan bahasa yang dimengerti oleh komputer untuk memberikan suatu instruksi. Pada dasarnya komputer adalah sebuah mesin digital, artinya komputer hanya mengenal kondisi adanya arus (dilambangkan sebagai angka 1) atau tiadanya arus (dilambangkan sebagai angka 0). Dengan kata lain sandi 1 dan 0 harus digunakan untuk melakukan pemrograman. Sandi tersebut dikenal sebagai bahasa mesin. Kita dapat membayangkan bagaimana sulitnya menggunakan bahasa mesin sebagai bahasa pemrograman..

Karena bahasa mesin sangat sulit maka muncul ide untuk melambangkan untaian sandi 1 dan 0 dengan singkatan kata yang mudah dipahami manusia. Sebagai contoh dalam prosesor Intel terdapat perintah
001110100000 1011. Perintah dalam bahasa mesin ini artinya sama dengan perintah assembly CMP AL, OD yang artinya bandingkan nilai register $A L$ dengan $0 D$. CMP sebenarnya adalah singkatan dari compare. Dapat dilihat disini bahwa perintah tersebut lebih mudah dipahami dibandingkan dengan urut-urutan bilangan biner seperti tersebut diatas.

Pemrograman dengan bahasa assembly untuk banyak orang masih dirasakan terlalu sulit. Karena hal tersebut akhirnya dikembangkan suatu bahasa pemrograman yang lebih yang lebih mudah digunakan. Bahasa pemrograman ini menggunakan bahasa generasi ketiga atau disingkat 3GL, biasa juga disebut sebagai high-level language.

Contoh dari bahasa ini adalah bahasa Basic, Pascal, C, C++, COBOL, dsb

Bahasa generasi ketiga biasanya menggunakan kata-kata dalam bahasa Inggris karena bahasa Inggris merupakan bahasa internasional. Sebagai contoh anda dapat menuliskan perintah berikut dalam bahasa Pascal. Sebagai contoh :

$$
\begin{aligned}
& \text { writeln ('Hallo'); }\{\text { Pascal }\} \\
& \text { printf (“Hallo"); // C++ } \\
& \text { cout << “Hallo" << endl; // C }
\end{aligned}
$$

\section{.B.PEMBAHASAN / STUDI KASUS}


- Struktur data : Adalah untuk mengorganisasikan data sedemikian rupa sehingga implementasi (penerapan) atau pemeliharaan logika program menjadi lebih terstruktur.

- Bahasa Program Turbo Pascal : Program adalah kumpulan intruksi atau perintah yang disusun sedemikian rupa sehingga memiliki urutan logika yang tepat untuk menyelesaikan suatu persoalan. Dan aplikasi yang digunakan adalah Turbo Pascal.

- Algoritma dan Struktur Data : Algoritma adalah jantung semua program yang merupakan urutan langkah sistematis dan dirancang untuk menyelesaikan suatu masalah spesifikasi dan dengan usaha yang paling minimal.

- Karakter Algoritma :

1. Input

2. Output

3. Definite (jelas)

4. Efektive

5. Terminate (Berakhir)

\section{$\underline{\text { Struktur Program Pascal : }}$}




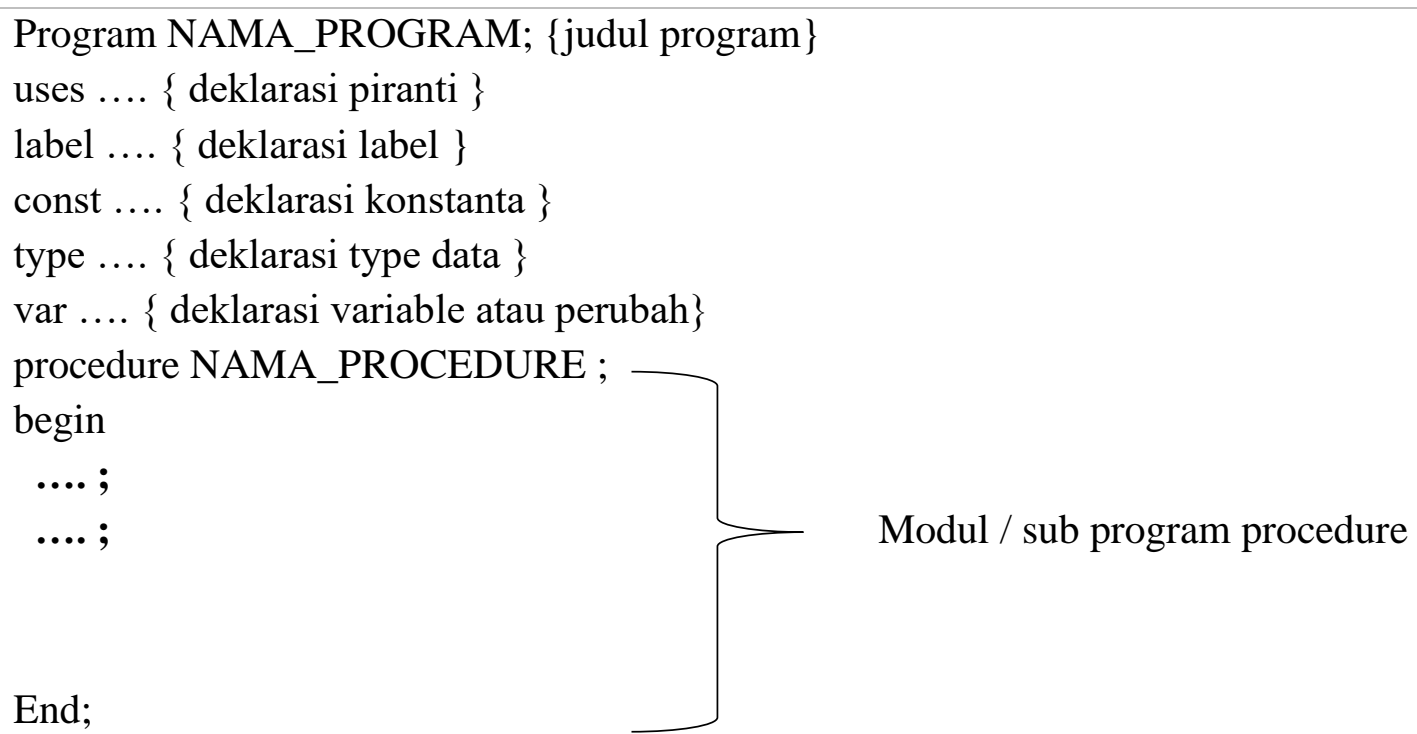

function NAMA_FUNCTION; begin $\ldots$;

End;

Begin $\{$ awal program utama $\}$

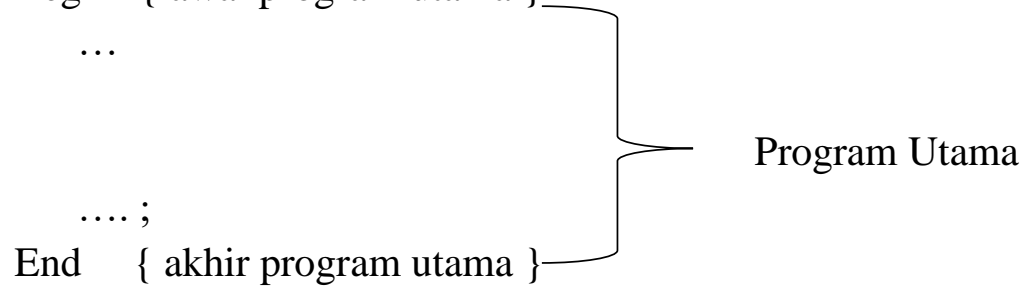

- Langkah - langkah Pembuatan Program

1. Mendefinisikan permasalahan

2. Membuat rumusan untuk memecahkan masalah Dapat disusun dalam bentuk pseudocode maupun flowchart Example : Pseudocode Mulai Input ( Bilangan 1 ) 


\section{Flowchart}

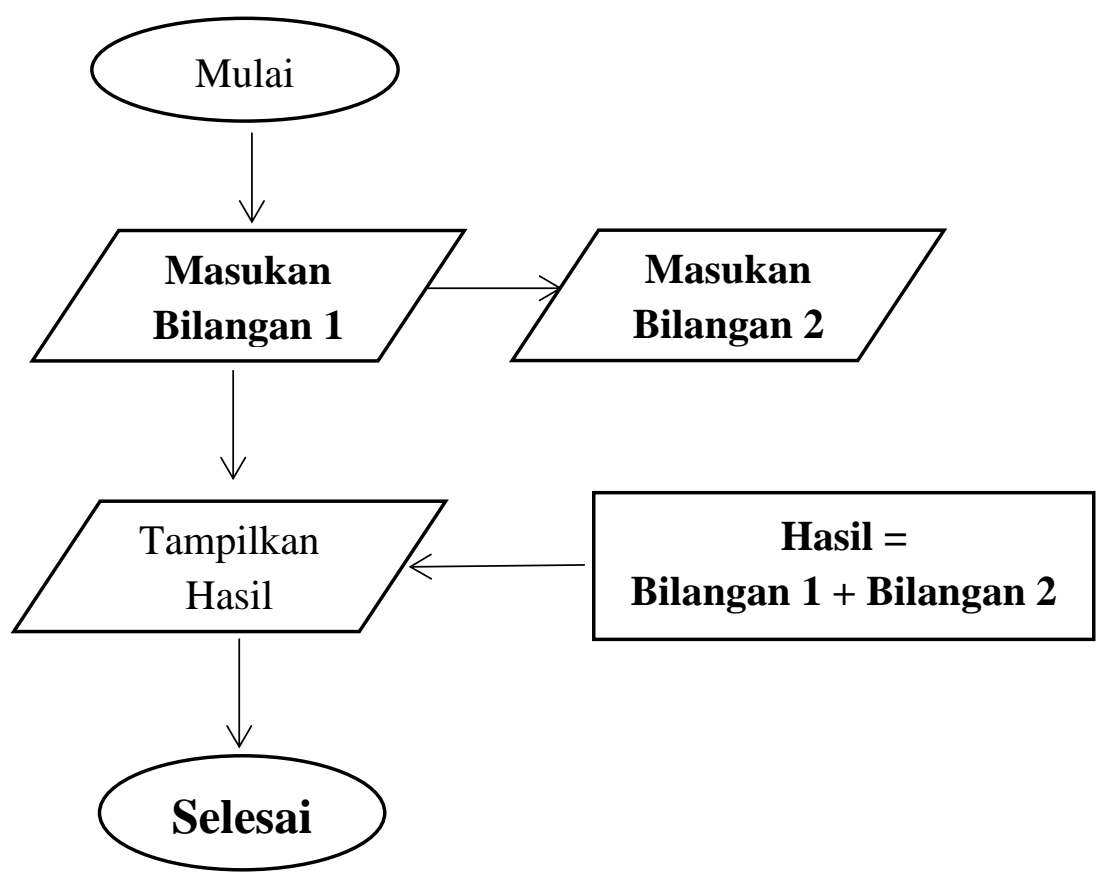

3. Implementasi \& Coding

4. Testing(menguju) dan membuat Dokumentasi

- Jenis-jenis Type Data

1. Type sederhana (simple type)

a. Type ordinal ( $\mathrm{u}$ semua bil. Kecuali bil real )

@ integer [ $32768 \ldots . .32767$ ] 2

bytes

@ shortint [ $128 \ldots . .127$ ] 1 bytes

@ longint [ 2147483648...21474 83647 ] 4 byte
@ boolen [

benar...salah] 1 bytes

@ char [ u karakter 1 huruf ] 'A' 1 bytes

(ASCII)

@ byte [0...255] 1 bytes

b. Type real ( u bil. Desimal ) 6 bytes

2. Type string ( data yang berisi sederetan karakter )

'INFORMASI'

3. Type terstruktur (Structured Type ) untuk ukuran tempat

a. Larik ( Array ) mempunyai jumlah data dalam jumlah tetap, tapi deangan type data yang sama, Contoh : [1...100]

b. Rekaman ( record) sama dengan array, tapi rekaman tidak harus dengan type data yang sama.

c. Himpunan ( set) kumpulan objek yang mempunyai type data sama.

d. Berkas ( file ) kumpulan sejumlah komponen yang bertype data sama. 
4. Type Pointer ( dijelaskan dalam sub SENARAI

BERANTAI)

- Contoh Type ARRAY :

VAR nilai : ARRAY

[1..maks_mha] of

char

- Contoh Type RECORD :

TYPE rec_mhs = record

Nim : string (10);

Nama : string (20);

Jur : sring (15);

End;

\section{ID SECURITY \\ QWTD4452377-ASP-5244166}

\section{D.KESIMPULAN}

Berdasarkan materi yang saya rangkum bahwa algoritma dan struktur data, dapat: 1. Memudahkan dalam mengembangkan program

2. Menghemat ukuran program

Beberapa hal yang harus diperhatikan dalam pembuatan fungsi adalah :

1. Fungsi menerima masukan yang disebut argumen atau parameter. 2. Masukan diproses oleh fungsi dan memberikan hasil akhir yang disebut nilai balik (return value).

3. Agar fungsi dapat dipanggil, fungsi harus dideklarasikan.
6. Prototipe

Deklarasi fungsi disebut prototype fungsi yang berupa :

1. nama fungsi

2. tipe nilai balik fungsi

3. jumlah dan tipe argument

4. serta diakhiri dengan titik koma (;). Contoh :

long kuadrat(long l)

dimana menyatakan kuadrat() adalah

nama fungsi, long adalah tipe argument, long (kedua) menunjukkan nilai balik yang bertipe long void garis() menyatakan fungsi tanpa nilai balik

\section{E.DISKUSI}

Saya bersama teman saya mendiskusikan tentang algoritma dan struktur data.

Jadi Algoritma adalah logika, metode dan tahapan (urutan) sistematis yang digunakan untuk memecahkan suatu permasalah.

Struktur data adalah cara menyimpan atau merepresentasikan data di dalam komputer agar bisa dipakai secara efisien Sedangkan data adalah representasi dari fakta dunia nyata.

\section{F.REFERENCE}


[1] O. M. Febriani and A. S. Putra, "Sistem Informasi Monitoring Inventori Barang Pada Balai Riset Standardisasi Industri Bandar Lampung," J. Inform., vol. 13, no. 1, pp. 90-98, 2014.

[2] A. S. Putra, "Paperplain: Execution Fundamental Create Application With Borland Delphi 7.0 University Of Mitra Indonesia,” 2018.

[3] A. S. Putra, "2018 Artikel Struktur Data, Audit Dan Jaringan Komputer," 2018.

[4] A. S. Putra, "ALIAS MANAGER USED IN DATABASE DESKTOP STUDI CASE DB DEMOS."

[5] A. S. Putra, "COMPREHENSIVE SET OF PROFESSIONAL FOR DISTRIBUTE COMPUTING."

[6] A. S. Putra, "DATA ORIENTED RECOGNITION IN BORLAND DELPHI 7.0."

[7] A. S. Putra, "EMBARCADERO DELPHI XE 2 IN GPU-POWERED FIREMONKEY APPLICATION.”

[8] A. S. Putra, "HAK ATAS KEKAYAAN INTELEKTUAL DALAM DUNIA TEKNOLOGY BERBASIS REVOLUSI INDUSTRI 4.0."

[9] A. S. Putra, "IMPLEMENTASI PERATURAN PERUNDANGAN UU. NO 31 TAHUN 2000 TENTANG DESAIN INDUSTRI
BERBASIS INFORMATION TECHNOLOGY."

[10] A. S. Putra, "IMPLEMENTATION OF PARADOX DBASE."

[11] A. S. Putra, "IMPLEMENTATION OF TRADE SECRET CASE STUDY SAMSUNG MOBILE PHONE."

[12] A. S. Putra, "IMPLEMENTATION PATENT FOR APPLICATION WEB BASED CASE STUDI WWW. PUBLIKLAMPUNG. COM."

[13] A. S. Putra, "IMPLEMENTATION SYSTEM FIRST TO INVENT IN DIGITALLY INDUSTRY."

[14] A. S. Putra, "MANUAL REPORT \& INTEGRATED DEVELOPMENT ENVIRONMENT BORLAND DELPHI 7.0."

[15] A. S. Putra, "PATENT AS RELEVAN SUPPORT RESEARCH.”

[16] A. S. Putra, "PATENT FOR RESEARCH STUDY CASE OF APPLE. Inc."

[17] A. S. Putra, "PATENT PROTECTION FOR APPLICATION INVENT."

[18] A. S. Putra, "QUICK REPORT IN PROPERTY PROGRAMMING."

[19] A. S. Putra, "REVIEW CIRCUIT LAYOUT COMPONENT REQUIREMENT ON ASUS NOTEBOOK." 
[20] A. S. Putra, "REVIEW TRADEMARK PATENT FOR INDUSTRIAL TECHNOLOGY BASED 4.0."

[21] A. S. Putra, "TOOLBAR COMPONENT PALLETTE IN OBJECT ORIENTED PROGRAMMING."

[22] A. S. Putra, "WORKING DIRECTORY SET FOR PARADOX 7."

[23] A. S. Putra, "ZQUERY CONNECTION IMPLEMENTED PROGRAMMING STUDI CASE PT. BANK BCA Tbk."

[24] A. S. Putra, D. R. Aryanti, and I. Hartati, "Metode SAW (Simple Additive Weighting) sebagai Sistem Pendukung Keputusan Guru Berprestasi (Studi Kasus: SMK Global Surya)," in Prosiding Seminar Nasional Darmajaya, 2018, vol. 1, no. 1, pp. 85-97.

[25] A. S. Putra and O. M. Febriani, "Knowledge Management Online Application in PDAM Lampung Province," in Prosiding International conference on Information Technology and Business (ICITB), 2018, pp. 181-187.

[26] A. S. Putra, O. M. Febriani, and B. Bachry, "Implementasi Genetic Fuzzy System Untuk Mengidentifikasi Hasil Curian Kendaraan Bermotor Di Polda Lampung," SIMADA (Jurnal Sist. Inf. dan Manaj. Basis Data), vol. 1, no. 1, pp. 21-30, 2018.

[27] A. S. Putra, H. Sukri, and K. Zuhri, "Sistem Monitoring Realtime Jaringan Irigasi Desa (JIDES) Dengan Konsep Jaringan Sensor Nirkabel," IJEIS (Indonesian J. Electron. Instrum. Syst., vol. 8, no. 2, pp. 221232.

[28] D. P. Sari, O. M. Febriani, and A. S. Putra, "Perancangan Sistem Informasi SDM Berprestasi pada SD Global Surya," in Prosiding Seminar Nasional Darmajaya, 2018, vol. 1, no. 1, pp. 289-294. 